\title{
Polyornithine-based polyplexes to boost effective gene silencing in CNS disorders
}

Received 00th January 20xx, Accepted 00th January 20xx

DOI: $10.1039 / x 0 x x 00000 x$

\author{
I. Conejos-Sánchez ${ }^{a, b(*)}$, E. Gallon ${ }^{a}$, A. Niño-Pariente ${ }^{a}$, J. A. Smith ${ }^{b, d}$, A. G. De la Fuente ${ }^{b, c}$, L. DiCanio $^{b, c}$, \\ S. Pluchino ${ }^{b}$, R.J.M. Franklin ${ }^{b, c}$, M.J. Vicent ${ }^{a}\left(^{*}\right)$
}

Gene silencing therapies have successfully suppressed the translation of target proteins, a strategy that holds great promise for the treatment of central nervous system (CNS) disorders. Advances in the current knowledge on multimolecular delivery vehicles are concentrated on overcoming the difficulties in delivery of small interfering (si)RNA to target tissues, which include anatomical accessibility, slow diffusion, safety concerns, and the requirement for specific cell uptake within the unique environment of the CNS. The present work addressed these challenges through the implementation of polyornithine derivatives in the construction of polyplexes used as non-viral siRNA delivery vectors. Physicochemical and biological characterization revealed biodegradability and biocompatibility of our polyornithine-based system and the ability to silence gene expression in primary oligodendrocyte progenitor cells (OPCs) effectively. In summary, the well-defined properties and neurological compatibility of this polypeptide-based platform highlight its potential utility in the treatment of CNS disorders.

\section{Introduction}

Gene therapy based on small interfering RNA (siRNA) represents a clinically-applicable therapeutic stratey [1]; however, setbacks concerning delivery have hampered development and highlighted important considerations for clinical translation. Enzymatic degradation, insufficient circulation lifetimes, reduced tissue penetration, cell endocytosis, and cytosolic transport often represent insurmountable biological barriers for unmodified siRNA. As a result, gene-silencing technology has only recently gained approval for clinical applications after almost two decades of intense research and development [2]. Patisiran ${ }^{\circledR}$ (ALN-TTRO2 [Alnylam]), the first therapy based on RNA interference (RNAi), is intended to treat transthyretin (TTR) amyloidosis by reducing the levels of a mutated protein whose fibrils accumulate and impact heart and nerve system function. The lipopeptide nanoparticles (NPs) transporting anti-mutant TTR siRNA [3] accumulate in the liver and kidney, the desired target for siRNA function. This successful therapeutic demonstration of a

\footnotetext{
a. Centro de Investigación Príncipe Felipe. Polymer Therapeutics Laboratory, C/ Eduardo Primo Yúfera, 3, 46012 Valencia, Spain

b. Dept. Clinical Neurosciences and NIHR Biomedical Research Centre, Clifford Allbutt Building-Cambridge Biosciences Campus, University of Cambridge, United Kingdom

c. Wellcome Trust-Medical Research Council Stem Cell Institute, University of Cambridge, Hills Road, CB2 OPY Cambridge, United Kingdom

d. Cambridge Innovation Technologies Consulting (CITC) Limited, St. John's Innovation Centre, Cowley Road, CB4 OWS Cambridge, UK

$\left.+{ }^{*}\right)$ Corresponding authors.mjvicent@cipf.es, iconejos@cipf.es

Electronic Supplementary Information (ESI) available: [details of any supplementary information available should be included here]. See DOI: 10.1039/x0xx00000x
}

nanotechnological approach to siRNA delivery sparked renewed interest in RNAi-based therapies. Alnylam, also presents in its pipeline liver targeted siRNA-based gene therapy strategy: GalNAc-SiRNA conjugates [4]. The most advance example is Givosiran ${ }^{\circledR}$ for acute hepatic porphyria with excellent results in phase III clinical trials and has been very recently submitted for marketing authorization to the European Medicine Agency (EMA) [5].

siRNA therapeutics show promise for the treatment of a variety of otherwise untreatable pathologies, including central nervous system (CNS) conditions [6] thataffect more than one billion people worldwide, yet suffer from a lack of therapeutics. siRNA can silence/ downregulate disease-related gene expression, including those traditionally considered to be undruggable, expanding putative therapeutic capabilities beyond traditional small-molecule drug-based approaches. siRNA also represents an ideal therapeutic candidate for chronic CNS disorders whose treatment requires long-term administration. Moreover, the high specificity of siRNA reduces unwanted side effects in the brain [6, 7]. Finally, RNA-based technologies are fast and relatively easy to develop, thanks to well-defined synthetic routes and bioinformatics tools that facilitate target identification.

Of the $>60$ clinical trials involving siRNAs [8-10], less than $7 \%$ deal with CNS-related pathologies like glioblastoma, amyotrophic lateral sclerosis or multiple sclerosis (MS) [11]. Most research remains in early preclinical stages, as applications rely on effective blood-brain barrier (BBB) crossing while the therapeutic window for patient safety remains difficult to achieve. Among the nanotechnological platforms investigated for siRNA delivery, non-viral vectors represent a 
favorable alternative to viral vectors. The clinical implementation of viral vectors has been restricted due to biosafety risks, uncertainties regarding the causes of adverse effects, low gene capacity, and inferior targeting [12]. Non-viral vectors are ostensibly less immunogenic and easier/cheaper to manufacture [13]. Polymer-based gene delivery systems are particularly enticing given an inherent structural/chemical versatility that facilitates control over physicochemical properties, vector stability, and larger gene capacity [14] Furthermore, polymer-based systems display compatibility with good manufacturing practices and reproducibility in anticipation of translational manufacturing [15].

Cationic polymers interact with siRNA via electrostatic interaction, resulting in polyplexes formation - multicomponent nanosystems belonging to the polymer therapeutics family [16]. To date, CALAA-01 represents the most successful example, comprising an siRNA targeting the M2 subunit of ribonucleotide reductase complexed with a transferrin-coated self-assembling cationic cyclodextrin polymer conjugated with polyethylene glycol (PEG) that targets tumor cells overexpressing the transferrin receptor [8]. Polymers commonly investigated for CNS-related applications include polyethyleneimine, PEGylated-poly(amidoamine) (PAMAM) systems or PEGylated- polyaminoacids[17]. Although polyplexes have successfully delivered siRNA to the brain via intravenous or intranasal routes in preclinical studies, neurotoxicity-related issues and off-target effects related to poor biodistribution can hamper clinical translation, thus requiring the development of optimized siRNA delivery systems.

Biodegradable polymers, such as polypeptides, possess advantageous characteristics related to the safe and effective function of drug delivery vehicles. As an example, Opaxio, a poly(L-glutamic acid) conjugated to paclitaxel, has demonstrated safety and tolerability in clinical trials for highgrade glioma and other cancer types $[18,19]$.

We selected poly-L-ornithine (PLO) as a candidate for siRNA delivery to the brain. Ornithine (Orn) is a naturally-occurring non-proteinogenic amino acid containing a primary amine in the pendant group that provides the positive charge necessary for oligonucleotide complexation. To date, applications of PLO and Orn include: (i) gene silencing by polyplex formation (plasmid [20-22], DNA [24], and siRNA [25] complexation), (ii) cell penetration [26], (iii) growth improvement and cell [27-29], and (iv) coating materials [30], overall displaying lower immunogenicity than other cationic polypeptides. PLO also provides for tighter/stronger oligonucleotide condensation at a lower mass [23, 31] and increased resistance anionic counter species-mediated disruption [23].

To our knowledge, this study is the first to exploit PLO as a gene delivery carrier to the CNS. We describe a biodegradable PLO-based platform synthesized by N-carboxy anhydride (NCA) polymerization in a reproducible/scalable manner, resulting in a polypeptide with a controlled degree of polymerization and narrow molecular weight (MW) distribution. After postpolymerization modifications, we created a library of PLOs that robustly form complexes with siRNA. Through an exhaustive physicochemical characterization, we also demonstrate the utility of this platform in terms of biocompatibility and biodegradability.

Aiming to mimic physiological conditions, we selected primary neural cells to evaluate gene silencing efficacy of novel polyplexes with a proposed application in the treatment of MS,. [32]. There is an immediate need for research into limiting MS progression, with a focus on delivering neuroprotective and neuroregenerative therapies. We explored our novel non-viral vectors as a means of promoting remyelination and axon regeneration by silencing death receptor 6 (DR6) viasiRNA delivery. Mi et al. [33] reported that DR6 negatively regulated oligodendrocyte (OD) survival, maturation, and myelination, and that attenuation of DR6 boosts remyelination and inhibits autoimmune activation in vivo. All OD subtypes express DR6 during maturation, including oligodendrocyte progenitor cells (OPCs), and DR6 overexpression induced caspase- 3 activation and cell death

Excitingly, our polyplexes provided sustained transfection efficiency in primary OPCs, a relevant in vitro model for potential neurotherapeutic applications. These results provide evidence for the promising future of PLO-based delivery in the development of siRNA-based therapies for CNS disorders.

\section{Results and Discussion}

\section{Synthesis and characterization of poly-L-ornithine}

\section{derivatives}

We selected PLO as a novel material with well-established potential in CNS applications to develop an efficient siRNA delivery system for the treatment of CNS disorders. Polyamino acids/polypeptides mimic natural proteins and possess demonstrated biocompatibility and biodegradability due to the endogenous nature of the monomeric building-blocks [43]. Often, biocompatible naturally-occurring biodegradable polymers (e.g. chitosan, cyclodextrins, etc.) present an inherent size heterogeneity (polydispersity index (PDI)>1.6) [44], which masks precise structure-activity relationships. Thus, to foster clinical translation it is required well-defined characterization and the minimization of variability through strict control of the production procedure.

The first innovation in this study relates to PLO synthesis; we synthesized PLO using a facile and versatile methodology based on ROP-NCA chemistry (ring-opening polymerization of $\alpha$ amino acid $\mathrm{N}$-carboxyanhydrides) that permits the reproducible 
generation of well-defined homogenous polypeptides [45]. This potent methodology allows for the synthesis of well-defined polypeptides on multigram scales and with low polydispersity (PDI <1.2), adjustable MW, controlled chain end-functionality, and robust stereoselectivity, all ideal features for biomedical applications and industrial development [46]. Currently published studies exploit PLOs with broad MW distributions and/or structural heterogeneity, which might impede drug development and regulatory approval. In our study, we synthesized PLO using ROP-NCA, giving a high-quality polymer with low polydispersity. As remarked before, these characteristics are crucial for further translational manufacturing.

PLO (P) derivatization resulted in the generation of four different products: P1 (PLO-2PD), P2 (PLO-PEG3000), P3 (PLOPEG3000Fmoc), and P4 (PLO-PEG2000) (Figures 1A and S2). The major concern driving the derivatization of PLO was to at least partly neutralize the cationic character of the main chain to decrease any associated cellular toxicity, minimize electrostatic interactions, reduce protein binding, and modulate nucleic acid complexation capabilities. Therefore, we introduced different moieties into the main chain by covalent linkage via the pendant amino groups. Interestingly, studies have demonstrated that aromatic molecules such as peptidic residues (e.g., tyrosine, phenylalanine, or tryptophan) or drugs (e.g., doxorubicin or daunomycin) can complex DNA/oligonucleotides [47-51]. Aromatic residues may intercalate into the nucleic acid base pairs, contributing to improved condensation and providing higher transfection efficiency. Therefore, we decided to study the stabilizing effect of introducing aromatic molecules into the polymer, e.g., pyridyl moieties (P1) and the Fmoc group (P3) (Figure 1A); the hydrophobicity of the Fmoc moiety in P3 may induce conformational changes in comparison with the P2 derivative. The pyridyl moiety can promote crosslinking with free amino groups via the reactive thiol group [52], which might contribute in creating clusters to better accommodate siRNA complexation. We also covalently attached PEG chains onto the polymer backbone pendant groups to increase polyplex steric stability and prevent non-specific interactions [53]. In the context of CNS disorders, PEGylation contributes to generating a near-neutral surface charge that favors the spread of the polymer throughout the brain [54-56]. Therefore, we examined two different PEGs (MW of $2,000 \mathrm{~g} / \mathrm{mol}(\mathrm{P} 2)$ and $3,000 \mathrm{~g} / \mathrm{mol}$ (P4)). Polymer derivatization can modify the polymer's in vivo fate, biodistribution, and thus, therapeutic activity.

We calculated the substitution degree of all derivatives (Figure 1B) from the corresponding peak intensity ratio between the PEG or 2PD (pyridyl disulfide) protons and the PLO protons in the 1 H-NMR spectra (Figure S3A-D). We observed different retention times upon analysis of the derivatives by gel permeation chromatography (GPC), indicating that differences in MW depend on the introduced motif (Figure 1C and S4). As part of the characterization of these novel derivatives, diffusion-ordered NMR spectroscopy (DOSY NMR) studies determined diffusion coefficients (Figure 1B) and proved the successful conjugation of the residues (2PD, PEG or PEG-Fmoc), verifying identity and purity. This diffusion coefficient is inherent to the product and relates not only to intrinsic properties (size, shape, MW, charge, etc.) but also to the surrounding environment (e.g., concentration, solvent, temperature, etc.). This technique has been applied in different contexts, including $\mathrm{MW}$ prediction, predicting the effect of 
shape in polymers, bioconjugation studies, and polypeptide studies [57-61].

NMR results indicated that, after derivatization, PEGderivatives displayed a slight increase in size, which further diminishes their diffusion coefficient. This data highlights the which can treble the initial hydrodynamic radius ( $\mathrm{Rh})$. In the case of 2PD derivation (P1), the diffusion coefficient (D) increases; the low MW of the 2PD molecule in comparison with the polymer and the possible conformation of the derivative result in a smaller size in solution than the polymer alone. We can speculate that the disposition of 2PD within a core
(A)<smiles>[X][C@H](C)CCC(NC)C(C)=O</smiles>

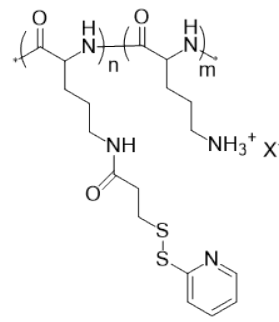

P1

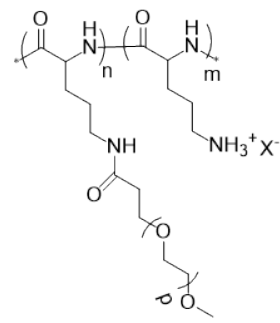

$\mathrm{P} 2(\mathrm{p}=68, \mathrm{PEG} 3000)$ $\mathrm{P} 4(p=46, \mathrm{PEG} 2000)$

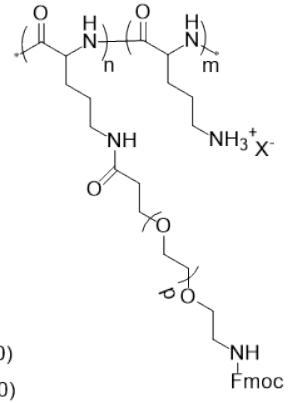

P3 $(p=68$, PEG3000)

(B)

\begin{tabular}{|c|c|c|c|}
\hline & & \%mol* & $D\left(\mathrm{~m}^{2} / \mathrm{s}\right)^{\#}$ \\
\hline PLO & $\mathbf{P}$ & - & 4,43E-11 \\
\hline PLO- 2PD & P1 & 8 & $4,96 \mathrm{E}-11$ \\
\hline PLO - PEG3000 & $\mathbf{P 2}$ & 1,4 & $4,08 \mathrm{E}-11$ \\
\hline PLO - PEG3000-Fmoc & P3 & 2,7 & $4,11 \mathrm{E}-11$ \\
\hline \multirow[t]{2}{*}{ PLO - PEG2000 } & P4 & 1,8 & $4,12 \mathrm{E}-11$ \\
\hline & & $\begin{array}{c}*^{1} \mathrm{H}-\mathrm{NMR} \\
\left(\mathrm{D}_{2} \mathrm{O}\right)\end{array}$ & $\begin{array}{c}{ }^{\#} \text { DOSY } \\
\left(D_{2} O\right)\end{array}$ \\
\hline
\end{tabular}

(C)

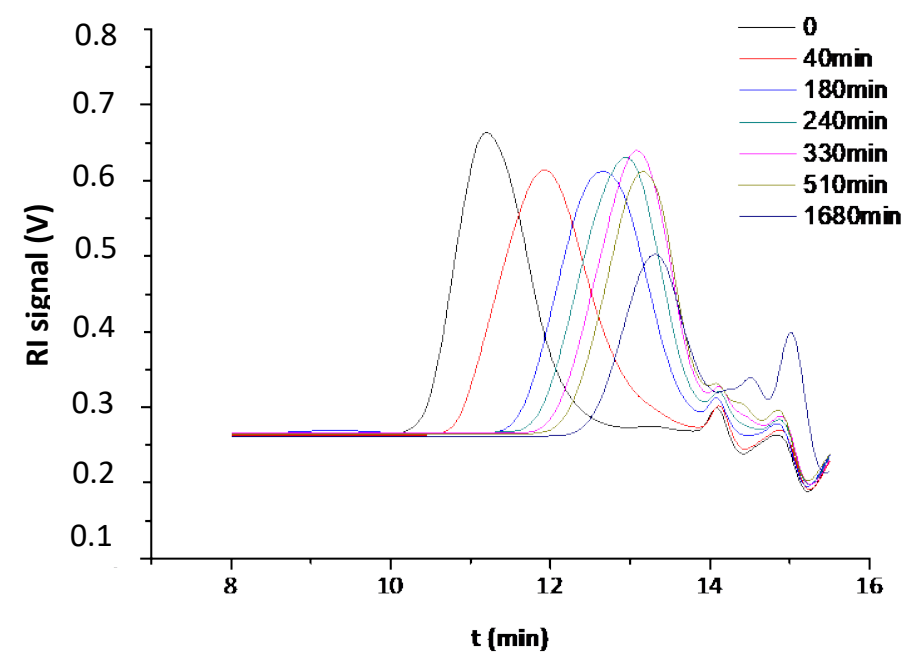

Figure 1. (A) Poly-L-ornithine derivatives (P1-P4). (B) Molar percentage of modification calculated by $1 \mathrm{H}-\mathrm{NMR}$ and diffusion coefficients of the obtained derivatives by DOSY. (C) Degradation of P2 monitored by GPC (PLO150).

influence of the conjugated moieties on the size in solution, 
interacting through $\pi-\pi$ interactions due to the aromaticity of the molecule can result in a more compact structure than PLO.

The use of polymeric systems based on amino acids as drug delivery carriers provides the advantage of fully biodegradable vehicles. Although ornithine is a non-essential amino acid, it is generated in the body through several mechanisms and degraded into non-toxic metabolites [62]. PLO degradation inside the human body has yet to be extensively studied [63], and polymer chemical modification might impact the degradation rate of the final construct. Therefore, we studied the biodegradability of the newly synthesized polymers under various enzymatic conditions. The protease cocktail mixture employed contained a non-specific enzymatic matrix composed of at least ten proteases [64]. Previous studies have demonstrated that trypsin, chymotrypsin, or papain fail to degrade PLO [65-67], although metallocarboxypeptidases can catalyze the hydrolysis of basic amino acids such as ornithine [68]. We observed the degradation of modified PLO by a protease cocktail (Figures 1C and S4) with no effect of PEG derivatization on the degradation of the polymer, supporting the adequacy of the derivative for in vivo purposes.

\section{Preparation and Characterization of siRNA Polyplexes}

We prepared PLO polyplexes (Px, Px1, Px2, Px3, Px4) by mixing siRNA (or dsDNA, where indicated) and the corresponding polymer at varying molar ratios of amines in PLO to phosphates in siRNA (define as N/P ratio). We assessed oligonucleotide complexation by gel shift assay to evaluate the best N/P ratio (Figure S5). Increased electrophoretic migration retardation was observed at higher N/P ratios, yet all ratios tested (N/P from 2 to 10) demonstrated successful complexation. We next assessed the in vitro biocompatibility of these novel polymers by colorimetric (3-(4,5-dimethylthiazol-2yl)-5-(3-carboxymethoxyphenyl)-2-(4-sulfophenyl)-2H-

tetrazolium) (MTS) viability assays in the B16-F10 melanoma cell line as a preliminary screening cell model for our PLO derivatives (Figure S6). N/P ratios 3 and 4 did not compromise cell viability, and we selected N/P ratio 3 for further experiments to use the least amount of polymer.
Dynamic light scattering (DLS) revealed that all polyplexes displayed similar physicochemical properties, including a hydrodynamic diameter of $30-60 \mathrm{~nm}$ and PDI below 0.2 , associated with a unimodal size distribution (Figures 2A and S7). Size comparison with hydrodynamic radius $\left(R_{h}\right)$ of parent polyplexes (Table S1) can indicate that compaction occurred due to siRNA complexation. We discovered the zeta-potential for the derivatized polyplexes to be roughly half the value of a PLO polyplex $(30 \pm 2 \mathrm{mV}$ ) (Figure $2 \mathrm{~A})$, confirming the expected decrease in charges after chemical modification. We observed a slightly neutral-to-positive final zeta-potential for the polyplexes (Px1-Px4). siRNA delivery generally required positively-charged carriers for electrostatic interactions with a negatively-charged oligonucleotide cargo. The cationic systems reported in the literature (e.g., PEI, PAMAM, etc.) are often affected by aggregation, toxicity, premature sequestration by phagocytic cells, and non-specific cell membrane and serum protein-interactions [69]. Thus, modulation of positive charges represents a critical issue that must be addressed during delivery vehicle optimization. Some comparable cationic polypeptidic graft copolymers have demonstrated their potential as biocompatible carriers for other biomedical applications [70].

Transmission electron microscopy (TEM) images confirmed the DLS-measured sizes of the polyplexes, which displayed a biconcave disc morphology (Figures 2B and S8). Due to the concentration-dependent limitations of the technique, we carried out a parallel DLS study to confirm that concentration did not affect the apparent polyplex size (Figure S9). In addition, we observed the same morphology for all derivatives at all tested concentrations.

Circular dichroism (CD) spectroscopy is a powerful tool for the study of dynamic alteration to secondary structures and the conformations adopted by biomolecules such as nucleic acids, proteins, or synthetic polypeptides under various conditions [71-73]. In this study, we employed far-UV analysis (180-250 $\mathrm{nm}$, where peptidic bonds reveal secondary structure characteristics) to estimate the influence of PLO main chain modification. Also, the application of this technique to certify 
the complexation process can confirm the interaction of the dsDNA/siRNA with the polymeric derivative. We selected phosphate buffer (PB) as a solvent to analyze all components. First, we confirmed the similarity of the dsDNA band pattern to that previously reported $[74,75]$. As expected, the unmodified PLO spectrum resembled that of a random coil structure (Figure S10A). All derivatives (P1-P4) demonstrated slight changes compared to unmodified PLO but still maintained the appearance of a random coil structure after chemical modification. Only P3 exhibited a marked increase in molar ellipticity at $195 \mathrm{~nm}$ and a small decrease at $\sim 220 \mathrm{~nm}$ that can likely be attributed to interactions among the Fmoc groups. Analysis of polyplexes suggested the retention of the ellipticity characteristic of their polymeric counterpart (Figure S10B). In the case of PEG derivatives (P2, P3, and P4), the differences observed in comparison with each correspondent derivative (e.g., shifts in the area $190-200 \mathrm{~nm}$ and at approx. $250 \mathrm{~nm}$ ) might be ascribed to complexation with the dsDNA, confirming the co-existence of both species in the polyplex. The conformation of PLO is downgraded when dsDNA is complexed, with the observation that Px2 and Px3 presented a higher prevalence of dsDNA structure and higher trend to adopt an alpha-helix conformation.

Next, we performed stability studies, mimicking in vitro or in vivo scenarios, to assess the ability of the polyplexes to release siRNA. We employed the polyanion heparin as an indicator of binding strength between siRNAs and cationic polymers $[76,77]$ as heparin acts as a competing polyanion, triggering polyplex disassembly. Our polyplexes (Px: 0.011, Px1: 0.015, Px2: 0.016, Px3: 0.022, Px4: $0.018 \mathrm{mg} / \mathrm{mL}$ ) demonstrated stability in the presence of up to $0.75 \mathrm{IU}$ of heparin per $20 \mu \mathrm{L}$ (this corresponds to $75 \mathrm{IU} / 100 \mathrm{~mL}$, well above the average heparin levels in human plasma, which only reach $15 \mathrm{lU} / 100 \mathrm{~mL}$ [78]) (Figure 2C). We applied an excess of heparin to prove siRNA/dsDNA release (1 IU per 20uL, $5000 \mathrm{IU} / 100 \mathrm{~mL}$ ), verifying the integrity of the polyplex under the selected conditions. Before in vitro experiments, we studied polyplex stability in B16-F10 and OPC cell media. Serum is often present in cell media and contains abundant polyanions, such as proteoglycans and glycosaminoglycans, that can promote oligonucleotide release from the complex. Encouragingly, we discovered complex stability after $\mathbf{2 4}$ hours of incubation in cell medium (with and without serum), thereby indicating the overall stability of polyornithine complexes (Figure S11).

Envisioning the possible intravenous (i.v.) administration of these novel polyplexes, we next determined blood stability of polyplexes and their ability to induce red blood cell (RBC) lysis as a means to predicting their integrity and safety for in vivo administration [79]. The RBC hemolysis assay can also help to determine $\mathrm{pH}$-dependent membrane disruption. Stability at $\mathrm{pH}$ 7.4 mimics the conditions faced by the polyplex following i.v. administration, as well as the $\mathrm{pH}$ in extracellular and cytosolic environments. All polyplexes and their parent polymers displayed $<5 \%$ hemolysis at $\mathrm{pH} 7.4$ when employing a polymer concentration range of $0.05-0.005 \mathrm{mg} / \mathrm{mL}$ (polymer content), thereby suggesting suitability for i.v. administration in this concentration range (Figure S12). At $0.1 \mathrm{mg} / \mathrm{mL}$, all polyplexes displayed hemolytic behavior at low pHs, suggesting possible efficient endosomal disruption/escape. For subsequent activity experiments, we employed a concentration of $0.05 \mathrm{mg} / \mathrm{mL}$ in the hope of maximizing dosage without reaching hemolytic levels. We further evaluated the stability of the siRNA polyplexes in blood (Figure 2D and S13). The complexes remained stable for at least $5 \mathrm{~h}$ in plasma, confirming their suitability for systemic delivery applications. Finally, we analyzed the stability of preformed polyplexes (in suspension) at $4^{\circ} \mathrm{C}$ for 15 days (Figure S14) to mimic relevant conditions for short-term storage. Of the four polyplexes, only Px2 displayed non-significant variations in both size and Z-potential (Px1 displayed a substantial increase in size over time, while both Px3 and Px4 underwent considerable Z-potential increases).

\section{In vitro Validation of PLO Polyplexes}


Once we demonstrated the ability of these novel polymeric with all polyplexes ( $\geq 85 \%$ for Px1, Px2 and Px3, and $\geq 75 \%$ for

(A)

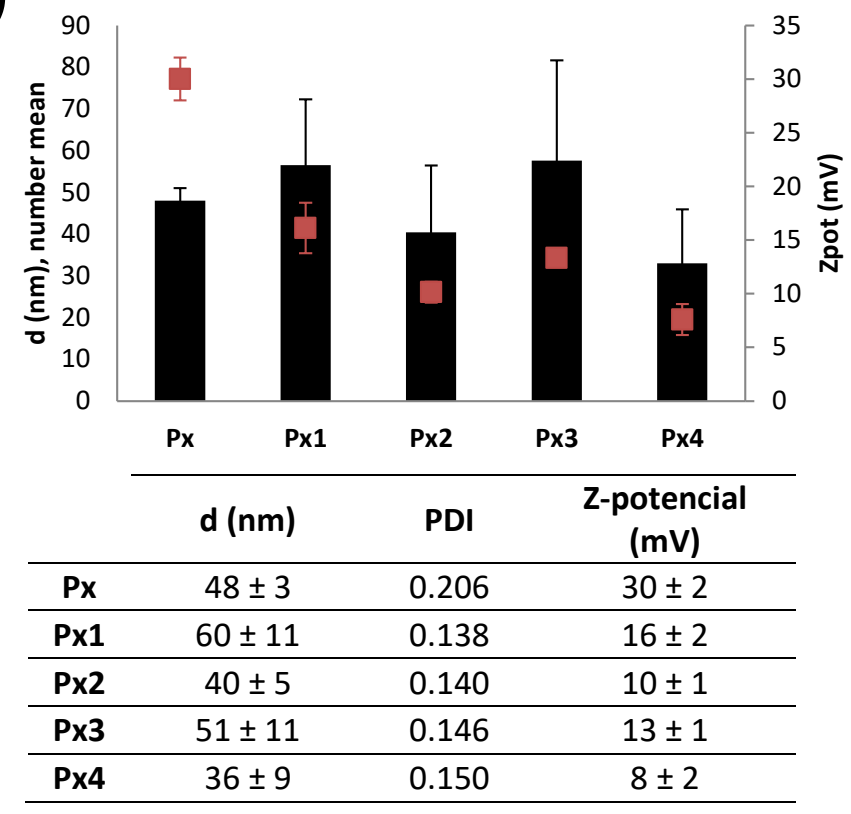

(B)

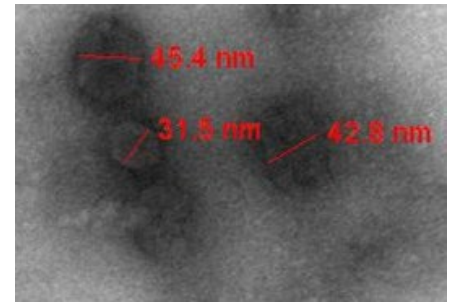

(D)

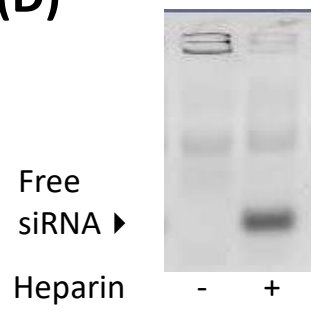

(C)

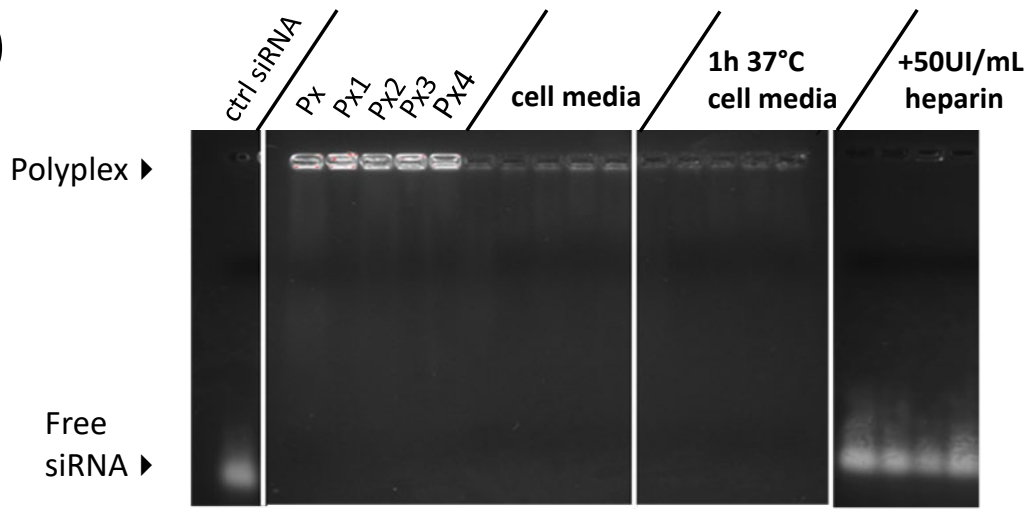

nanocarriers to form stable and biodegradable siRNA Px4) (Figure S15), independent of the siRNA payload (non-

Figure 2. (A) Study of size (black bars) and Z-potential (red squares) of the polyplexes by DLS [pol] $=0.012 \mathrm{mg} / \mathrm{mL}$ and (B) representative TEM images of the polyplex Px2 [pol] $=0.12 \mathrm{mg} / \mathrm{mL}$ (diameter $=44.7 \pm 10.5 \mathrm{~nm}$ ). (C) Stability studies by shift-gel assay of the polyplexes after their dilution in OPC cell media and after $1 \mathrm{~h}$ incubation at $37^{\circ} \mathrm{C} .1 \mathrm{IU} / \mathrm{mL}$ of heparin was added after the $1 \mathrm{~h}$ at $37^{\circ} \mathrm{C}$ incubation to disassemble the polyplex and verify the presence of the siRNA in the complex. NT = non-target siRNA. (D) Plasma stability assay of Px2 after $5 \mathrm{~h}$ of incubation.

complexes effectively, we next aimed to verify their biocompatibility and functionality as gene silencing vectors.

\section{Luciferase Inhibition}

Initially, we employed luciferase (luc) transfected cells (B16F10-luc-G5) as a cell model to quantify gene silencing, with luc as the reporter protein. Cell proliferation (MTS) assays carried out in B16-F10 cells revealed high cell viability after treatment targeted control (NT) or Luc), or the parent polymers (Figure S6). All the systems exhibited similar equivalent silencing of luciferase gene expression ( $50-68 \%$ reduction), thereby proving the capacity of PLO derivatives to deliver siRNA (Figure S16) efficiently. Given these encouraging results, we next tested these polyplexes in an in vitro model relevant to neurodegenerative disorders. 
Figure 3. Safety and gene silencing in primary OPCs. (A) LDH cytotoxicity assay $48 \mathrm{~h}$ post-transfection. $n>3$, mean \pm SEM. Indicated concentrations corresponds to siRNA. (B) qPCR assays showing the knockdown of Tnfrs 21 target mRNA by polyplexes. Downregulation measured $48 \mathrm{~h}$ after transfection. Lipofectamine or NT siRNA polyplexes were used as negative c(rAfpls. GAPPH was selected as the reference gene. (B) Study of PLO derivates at 100nM (siRNA concentration)

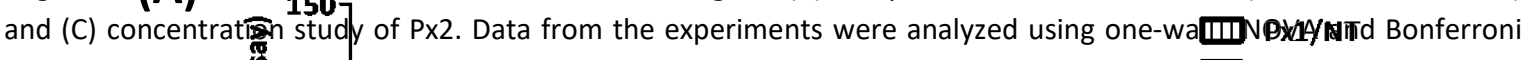
posthoc for pairwis

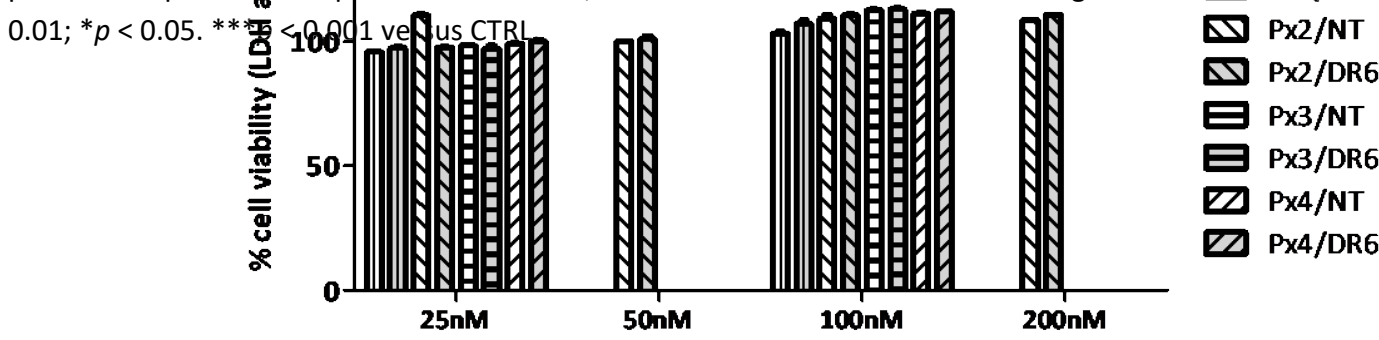

(B)

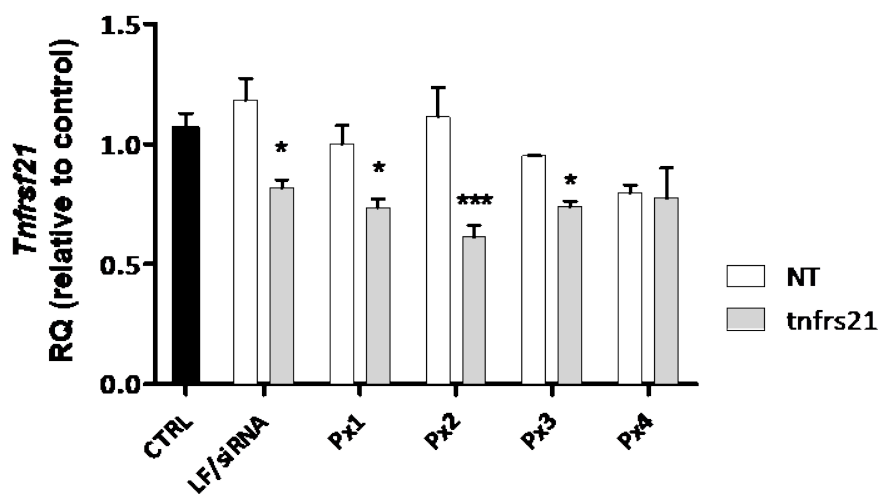

(C)

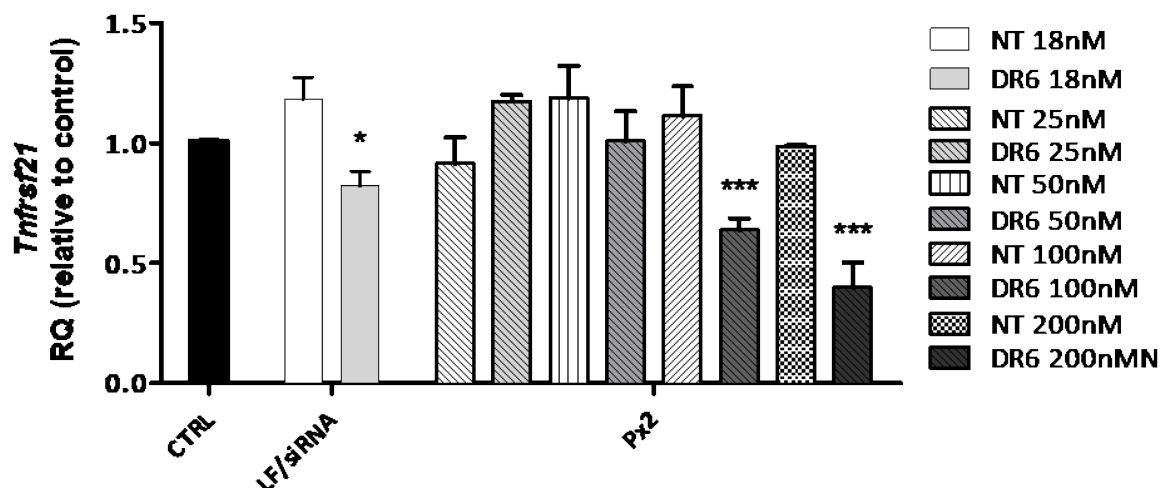

\section{DR6 Inhibition}

The Death receptor 6 (DR6) protein is involved in several neurodegenerative disorders. As a member of the tumor necrosis factor (TNF) receptor family (a.k.a. TNF receptor superfamily member 21 (TNFRSF21)), DR6 regulates apoptosis through caspases in a range of neural cell types [80, 81]. Upregulation of DR6 has been reported to result in (i) caspase 3 (Casp3) activation, axon degeneration, and motor neuron death in ALS [82], (ii) Casp6 and Casp3 activation and induction of axonal degeneration in prion-related diseases [83], and (iii) Casp3 activation, oligodendrocyte cell death, and demyelination [33]. In this latter example, Mi et al. described how DR6 attenuation enhanced oligodendrocyte maturation and myelination and inhibited autoimmune activation during in vivo studies in an animal model of MS. Recent studies also suggested that DR6 plays a role in T helper cell activation, with a potential role in inflammation and immune regulation [84, 85].

In this study, we focused on silencing DR6 in primary OPCs to validate our polyplexes as gene silencing vectors as a potential treatment for MS. Primary cells constitute a step up in complexity over immortalized cells in in vitro models, ostensibly providing a more realistic scenario, a critical point in the 
development of regenerative therapies in the CNS. We prepared OPCs from newborn rat brains as previously described [86], which involves A2B5 magnetic cell sorting to obtain pure OPC cultures (90\% A2B5+ cells) from the neonatal brain while avoiding the culture of cells in mixed glial cultures. This setup allows us to study the role DR6 silencing directly in OPCs, avoiding off-target effects that could happen in mixed glial cultures, as well as eliminating the presence of FBS in the media which is always a confounding factor.

Having established N/P 3 as the effective ratio for gene silencing, we tested several siRNA concentrations at this ratio in OPCs (from 25 to $200 \mathrm{nM}$ ). Transfection of OPCs with the polyplexes proved to be non-toxic for $48 \mathrm{~h}$ post-transfection at concentrations up to at least $100 \mathrm{nM}$, as verified by colorimetric LDH cytotoxicity assay (Figure 3A)

We then proceeded to study DR6 downregulation at mRNA and protein level. Transfection with Px1, Px2, and Px3 at $100 \mathrm{~nm}$ [siRNA] led to a decrease in Tnfrsf21 expression relative to nontransfected cells (35\%, $36 \%$ and $39 \%$, respectively), as observed in the analysis of mRNA levels via qPCR (Figure 3B). Delivery of NT negative control siRNA resulted in no significant change in the expression of Tnfrsf21. In comparison, siRNA-mediated knockdown using Lipofectamine (LF) as a transfection reagent yielded a lower silencing effect (18\%). Higher concentrations of LF as a transfection agent further enhanced gene silencing due to higher cytotoxicity in OPCs. A more exhaustive assay with Px2 revealed a dose-dependent silencing response, in which $200 \mathrm{nM}$ decreased Tfnrsf21 by $>60 \%$ (Figure $3 \mathrm{C}$ ). We do note that the only two of the four siRNAs that compose the siRNA pool targeted rat sequences; therefore, further optimizing the siRNA pool to more fully target the rat sequences may further potentiate the silencing effect.

At this stage, we selected P2 as the candidate with which to move forward with protein knockdown studies owing to its better stability, lower apparent cytotoxicity, and greater downregulation efficacy in qPCR studies. We chose a siRNA concentration of $100 \mathrm{nM}$ and performed protein collection four days post-transfection, as downregulation of DR6 was not observed until $48 \mathrm{~h}$ after gene silencing (Figure S17). Px2/DR6 induced a significant reduction in DR6 protein expression (Figure 4A); DR6 levels decreased 34\% upon Px2/DR6 treatment relative to the non-treated control. Interestingly, Lipofectamine (LF/DR6) failed to silence DR6 at the protein level at $48 \mathrm{~h}$ or 4 days after transfection (Figure S17), suggesting the potent nature of our newly developed polyplexes. We examined poly(ADP-ribose) polymerase (PARP) expression to assess the effect of DR6 silencing on Casp3 activation. PARP is a Casp3 substrate whose cleavage constitutes a hallmark of apoptotic cells $[85,86]$. A 49\% reduction in PARP upon Px2/DR6 treatment (Figure 4A) verified the correlation between DR6 and Casp3 established in the literature. However, when we analyzed the expression levels of proteins known to be markers of OPC differentiation and maturation after DR6 knockdown, including 2',3'-cyclic-nucleotide 3'-phosphodiesterase (CNP), myelinassociated glycoprotein and myelin oligodendrocyte glycoprotein, we did not observe any differences between treated and control samples (Px and LF) (Figure 4B). To validate this result, we performed further qualitative assessments of OPC maturation markers by immunofluorescence assays. To determine OPC maturation after DR6 silencing, we addressed the various differentiation/maturation stages using three different markers: Olig2 a pan-oligodendrocyte marker staining OPCs and mature oligodendrocytes; O4, a marker for immature and mature oligodendrocytes; and CNP, a marker for mature oligodendrocytes [89]. We analyzed the proportion of Olig2+ cells expressing the immature marker $\mathrm{O} 4$ and the mature marker CNPase and observed no differences between those treated with control NT siRNA polyplexes or DR6 siRNA polyplexes. Despite DR6 knockdown at the gene and protein level, this downregulation seemed to have no effect on the ability of OPCs to differentiate into mature oligodendrocytes, nor their morphology (Figure S18). Therefore, protein analysis by Western blot and immunocytochemical analysis of OPC differentiation revealed that independent to the efficacy of the polyplexes to silence DR6 in OPCs, DR6 silencing did not translate into enhanced OPC maturation as published previously [33]. 
(A)
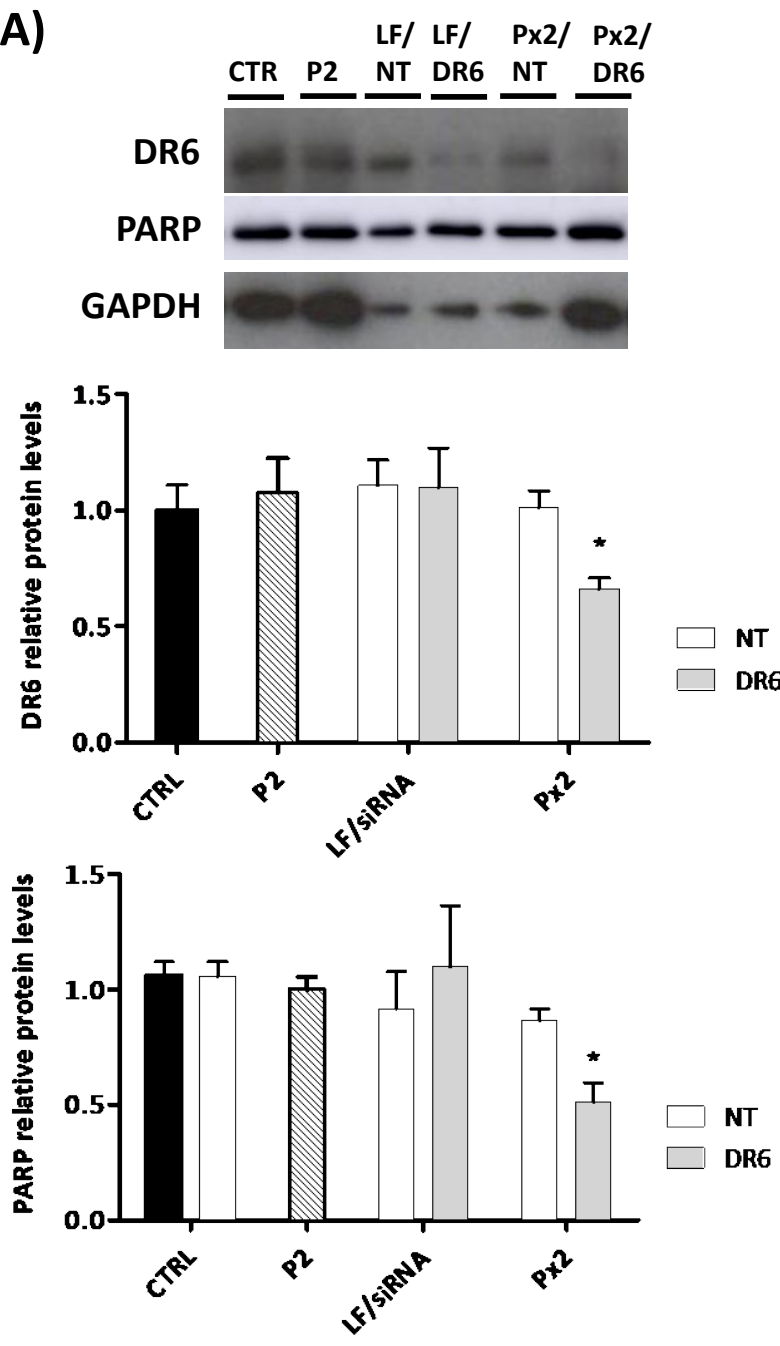

In parallel with these studies, we evaluated cell viability and gene silencing efficiency in other neural cell types. For example,
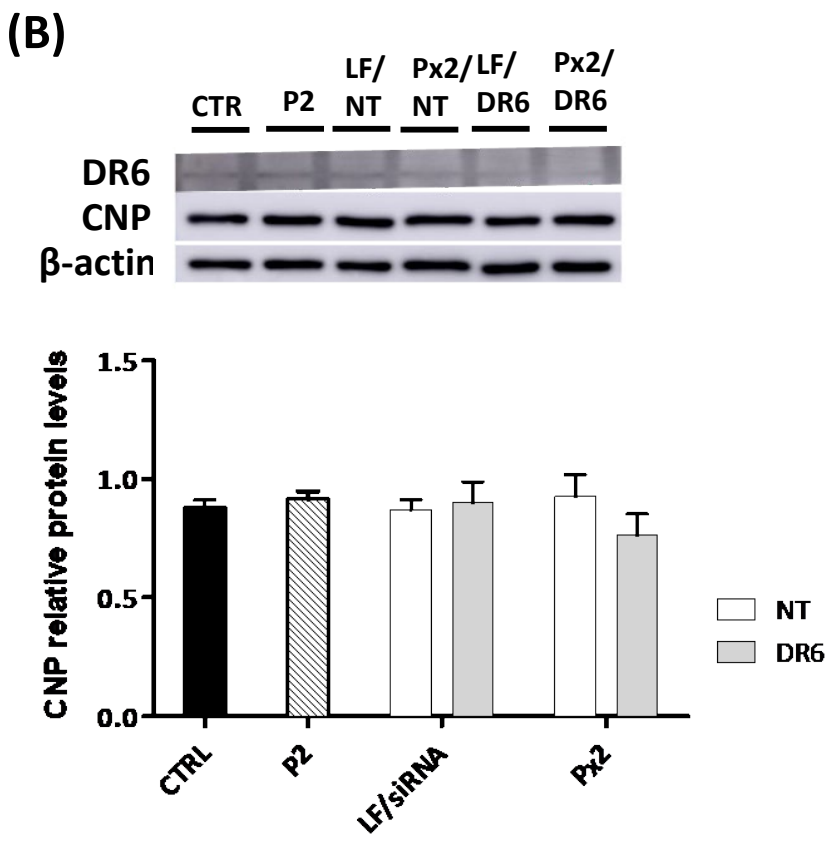

Figure 4. Densitometry-based quantification of (A) DR6 (68 KDa), cleaved PARP (89 KDa), and (B) CNP (48 KDa) Western blots showing siRNA-induced protein knockdown and a representative image. Quantification is expressed relative to $\beta$ actin and normalized to non-transfected control samples.

we observed that our Pxs were non-cytotoxic in neural stem cells (NSCs), NSC-derived astrocytes, and two immortalized OPC cell lines: CG-4 [90, 91] and BO-1 [92] (Figure S19A-C). Additionally, did not succeed in downregulating DR6 in any of these cell lines (NSCs, BO-1, and CG-4), supporting the relevance of primary cell culture as a more realistic in vitro model for our aims, and the marked biocompatibility of our polyplexes with different brain cells.

\section{Conclusions}

making siRNA a feasible therapeutic approach for the treatment of CNS disorders. Previously reported non-viral systems have succeeded in effective brain delivery via i.v. or intranasal routes in preclinical studies; however, clinical translation of such platforms can be hampered by neurotoxicity-related problems and/or off-target effects due to inadequate biodistribution. To address these critical problems, we described, for the first time, novel biodegradable PLObased polyplexes for the delivery of siRNA to neural cells. This amino acid-based synthetic polymer exhibits several advantages over previously-reported systems. First, we obtained a well-defined and 
homogenous polypeptide through a robust and scalable polymerization procedure.

Moreover, we accomplished PEG-derivatization employing a well-established and straightforward methodology that did not alter the secondary structure of the main polypeptidic chain, as demonstrated by CD. Secondly, we established platform biodegradability, addressing the critical concern of drug carrier degradation after siRNA delivery. These characteristics are amenable to the future industrial scale-up of manufacturing as well as clinical translation.

The modification of the well-defined PLO chain with different PEG motifs or the small molecule 2PD gave rise to systems that formed complexes with siRNA. These nanocarriers facilitated oligonucleotide delivery by improving their stability in vitro and under in vivo-mimicking conditions. With neurological disorders commonly affecting specific parts of the CNS, and even subphenotypes of neural cells, the route of administration is a crucial aspect of nucleic acid delivery [69]. Envisioning the i.v. administration of our PLO-derivatives, we demonstrated stability in the bloodstream, with complexes remaining intact for at least $5 \mathrm{~h}$. Also, they were found to be non-haemolytic. For i.v. delivery, the final design will include a blood-brain barrier-targeting moiety (e.g., the Angiopep2 peptide) to favor uptake [17]. Another possibility will be the formulation of our polyplexes for intranasal administration, providing a direct delivery via nose-to-brain pathway [17].

Furthermore, increased selectivity towards the final target cell through the incorporation of another cell-specific targeting moiety will be required to realize the full potential of this proposed siRNAbased therapy. Fortunately, the multifunctional nature of PLO facilitates the conjugation of multiple moieties within the same polymer main chain. For intranasal administration, the inclusion of our PLO-derivative in a polymeric hydrogel, creating a multicomplex system, will endow the carrier with increased nose-to-brain delivery [14].

As a preliminary proof of activity, we successfully employed PLO complexes in the transfection of B16-F10 cells, as demonstrated by luciferase assay. Further evaluation of therapeutically active polyplexes in primary OPCs underpinned their efficacy in silencing DR6, as established by qPCR assays. Px2 (PLO-PEG3000) demonstrated the highest silencing efficiency, suggesting the relevance of the MW of the introduced PEG. We observed a concomitant reduction in DR6 and PARP protein expression, thus corroborating the reported connection between DR6 and cell death through the Casp3 pathway. However, we found no evidence of effects on OPC differentiation and maturation after DR6 silencing Regardless of this fact, our polyplexes have shown their ability to facilitate gene silencing in primary neural cells, in parallel with their biocompatibility with other neural cell types. Within this context we would like to draw attention to the vital importance of the selection of the in vitro model, because our nanocarriers worked efficiently with primary cells. In addition, our polyplexes were found to be safe in a diversity of brain cells.

In summary, we have described the implementation of novel biodegradable and biocompatible polyornithine derivatives as nonviral vectors for siRNA that effectively silence gene expression in primary neural cells. We postulate that this well-defined polypeptidic platform and its suitability for applications in neural cells will translate into effective therapies for the treatment of CNS disorders.

\section{Experimental}

Materials

Poly-L-ornithine (PLO, $5,700 \mathrm{~g} / \mathrm{mol}, \mathrm{n}=50, \mathrm{PDI}=1.09$ ) was provided by Polypeptide Therapeutic Solutions SL. (PTS; Valencia, Spain). 4-(4,6-Dimethoxy-1,3,5-triazin-2-yl)-4-methyl morpholinium chloride (DMTMM.Cl) salt was synthesized, according to Kunishima et al. [34] and the tetrafluoroborate salt (DMTMM·BF4) according to Kamiński et al. [36]. Pyridyl dithiol ethylamine $\mathrm{HCl}$ salt was synthesized as described in van der Vlies et al. [36]. All other chemicals were reagent grade and used without further purification. The mono or heterobifunctional poly(ethylene glycol) (PEG) derivatives mPEG(3000)-NHS (3,023 g/mol), Fmoc-PEG(3000)-NHS (3,219 $\mathrm{g} / \mathrm{mol}$ ) and $\mathrm{mPEG}(2000)-\mathrm{COOH}(2,015 \mathrm{~g} / \mathrm{mol})$, where NHS is $\mathrm{N}$ hydroxysuccinimide, and Fmoc is the fluorenylmethyloxycarbonyl protecting group, were supplied by Iris Biotech (Germany). 
$\mathrm{N}, \mathrm{N}$-dimethyl aminopyridine (DMAP), diisopropylethylamine (DIEA), ethylenediaminetetraacetic acid (EDTA), anhydrous dimethylsulfoxide (DMSO), poly-D-lysine (PDL, 70,000$150,000 \mathrm{~g} / \mathrm{mol}$ ), phenylmethanesulfonyl fluoride (PMSF), tris(hydroxymethyl)aminomethane (TRIS), and Streptomyces griseus protease cocktail were obtained from Sigma Aldrich. PD10 Columns Sephadex G-25 M for size exclusion chromatography (SEC) and ECL Prime Western Blotting System (RPN2232) were obtained from GE Healthcare. Deuterated solvents, such as deuterated oxide $\left(D_{2} O\right)$, were purchased from VWR (Spain). 4-(2-hydroxyethyl)-1-piperazineethanesulfonic acid (HEPES) was purchased from Biomol $\mathrm{GmbH}$, while agarose (Molecular Biology Grade) was obtained from Fisher Scientific. All siRNAs (sigENOME Mouse Tnfrsf21 (94185) siRNA SMARTpool, Luciferase GL3 Duplex (siRNA) and ON-TARGETplus Non-targeting Pool siRNA) were purchased from Dharmacon (Cultek, Spain). The QIAzol Lysis Reagent was purchased from QIAGEN, and the Complete Protease Inhibitor Cocktail was purchased from Roche. All RNA solutions and buffers were prepared using RNAase-free water.

Dulbecco's Modified Eagle's Medium (DMEM), phosphatebuffered saline (PBS), fetal bovine serum (FBS), penicillin, streptomycin, and trypsin were provided from Gibco Life technologies. The MTS and Bright-Glo Luciferase Assay systems were supplied by Promega. The LDH-Cytotoxicity Assay Kit II and radioimmunoprecipitation assay (RIPA) buffer (10X) were purchased from Abcam. High-Capacity cDNA Reverse Transcription kit was obtained from Life Technologies.

OPC isolation was performed using papain (Worthington), Hybernate A (produced in-house), DNase (Sigma-Aldrich), B27 (Gibco Life Technologies), 10\% pluronic acid (Gibco Life Technologies), Percoll (GE Healthcare), 10X PBS ( Gibco Life Technologies), 7.5\% Bovine Serum Albumin fraction $V$ (Gibco Life technologies), 0.5M EDTA pH=8.0 (Gibco Life technologies), recombinant insulin (Gibco life technologies), anti-Mouse A2B5 antibody (Millipore, MAB312), Anti IgM Microbeads (Miltenyi Biotech), and Magnetic Cell Separation kit from Miltenyi Biotech.

OPC media was composed of DMEM F12 (Gibco life technologies), $1.5 \mathrm{mM}$ sodium pyruvate, $25 \mathrm{mM}$ D-glucose
(Sigma Aldrich), $10 \mu \mathrm{g} / \mathrm{mL}$ insulin (Gibco life technologies), 60 $\mu \mathrm{g} / \mathrm{mL} \quad \mathrm{N}$-acetyl cysteine (Sigma-Aldrich), $50 \mu \mathrm{g} / \mathrm{mL}$ apotransferrin (Sigma-Aldrich), $16.1 \mu \mathrm{g} / \mathrm{mL}$ putrescine (SigmaAldrich), $40 \mathrm{ng} / \mathrm{mL}$ sodium selenite (Sigma-Aldrich), and 60 $\mathrm{ng} / \mathrm{mL}$ progesterone (Sigma-Aldrich). Growth factorsBasic fibroblast growth factor (bFGF) $(10 \mathrm{ng} / \mathrm{mL})$ and platelet-derived growth factor AA (PDGF-AA) $(20 \mathrm{ng} / \mathrm{mL})$ (Peprotech) were supplemented daily.

Cells were plated on $5 \mu \mathrm{g} / \mathrm{mL}$ PDL-coated plates at a density of either 143 cells $/ \mathrm{mm} 2$ or 31 cells $/ \mathrm{mm} 2$ depending on the experiment set-up.

Polyvinylidene difluoride (PVDF) transfer $0.45 \mu \mathrm{m}$ membranes for Western blotting, Lipofectamine RNAiMAX Transfection Reagent, TaqMan Fast Universal PCR Master Mix (2X) No AmpErase UNG, DR6 Taqman probe (Mm00446361_m1 Tnfrsf2), Mouse GAPDH endogenous control Taqman probe (4352339E), Halt Phosphatase Inhibitor Cocktail, and Pierce BCA Protein Assay kit were obtained from Thermo Fisher. The intercalating agent GelRed was purchased from Biotium/VWR. Immunofluorescence reagents: normal donkey serum (NDS) was acquired from Sigma-Aldrich. Primary antibodies: rabbit anti-Olig2 (AB9610) was obtained from Millipore; mouse antiCNPase (C5922) and Hoechst from Sigma-Aldrich and $\mathrm{O} 4$ from $R \& D$ systems. Fluoromount $G$ was obtained from Southern Biotech (Birmingham, AL) Primary antibodies western blot: Cleaved Caspase-3 (Asp175) \#9661 and poly(ADP-ribose) polymerase (PARP) \#9542 antibodies were acquired from Cell Signaling Technology. DR6/TNFRSF21 Antibody (NBP1-45952) was purchased from Novus Biologicals. A $\beta$-actin antibody was obtained from Merck Millipore. Secondary antibodies: Goat Anti-Rabbit IgG H\&L (HRP) (ab205718) was acquired from Abcam, mouse anti-rabbit IgG-HRP (sc2357) was obtained from Santa Cruz Biotechnology, Inc and anti-mouse IgG (A9044) from Sigma Aldrich.

\section{Methods}

1. Synthesis and Characterization of poly-L-ornithine Derivatives

\subsection{Synthesis of PLO50 Derivatives}


PLO-2PD (P1). One eq. of PLO50 Br salt (0.15 mmol, MW 195 per unit) was dissolved in $1 \mathrm{~mL}$ of PBS-EDTA $10 \mathrm{mM}$ under agitation at room temperature (RT). Then, 0.1 eq. of pyridyl dithiol cysteamine (2PD) previously dissolved in $200 \mu \mathrm{L}$ of DMSO was added dropwise to the PLO solution. The reaction was allowed to proceed for $1 \mathrm{~h}$ under agitation at RT. Then, the reaction volume was lyophilized, and the residue resuspended in double-distilled water $\left(\mathrm{dd}_{2} \mathrm{O}\right)$ and purified on a PD-10 column. Fractions were lyophilized and the obtained solid analyzed by $1 \mathrm{H}$ NMR and DOSY $\left(\mathrm{D}_{2} \mathrm{O}\right)$. $1 \mathrm{H}$ NMR $\delta \mathrm{H}(300 \mathrm{MHz}$, $\left.\mathrm{D}_{2} \mathrm{O}\right):$ 8.41-7.31 $(4 \mathrm{xH}, \mathrm{m}), 4.34(1 \mathrm{H}, \mathrm{m}), 3.21-3.06(4 \mathrm{xH}+2 \mathrm{H}, \mathrm{m})$, $1.82(4 \mathrm{H}, \mathrm{m}) . \mathrm{x}$ : percentage of modification.

PLO-PEG3000 (P2). All reagents were weighed in separate recipients and purged under N2 flow before and during their solution. In a two-necked round bottom flask, fitted with a stir bar and two septae, 1 eq. of PLO50 Br salt (0.15 mmol, MW 195 per unit) was dissolved in $2 \mathrm{~mL}$ anhydrous DMSO under magnetic stirring. Then, mPEG(3000)-NHS (0.01 eq.) dissolved in $1 \mathrm{~mL}$ DMSO was added to the flask followed by a catalytic amount of DMAP (previously dissolved in $200 \mu \mathrm{L}$ DMSO). pH was adjusted to 8 with DIEA, and the reaction was left under magnetic stirring for $36 \mathrm{~h}$. The solvent was removed under reduced pressure, and the product was re-suspended in $300 \mu \mathrm{L}$ of Milli-Q water and purified by size exclusion chromatography (G25, PD-10 column). Fractions were lyophilized and the obtained solids analyzed by $1 \mathrm{H} N \mathrm{NMR}$ and DOSY $\left(\mathrm{D}_{2} \mathrm{O}\right)$.

1H NMR $\delta H\left(300 \mathrm{MHz}, \mathrm{D}_{2} \mathrm{O}\right): 4.41(1 \mathrm{H}, \mathrm{m}), 3.74(68 \mathrm{xH}+4 \mathrm{H} \mathrm{m})$, $3.07(2 \mathrm{H}, \mathrm{m}), 1.82(4 \mathrm{H}, \mathrm{m})$. x: percentage of modification.

PLO-PEG3000Fmoc (P3). All reagents were weighed in separate recipients and purged under $\mathrm{N} 2$ flow before and during their solution. 1 eq. of PLO50 Br salt (0.15 mmol, MW 195 per unit) was dissolved in $2 \mathrm{~mL}$ DMSO anhydrous under magnetic stirring. Fmoc-PEG(3000)-NHS (0.01 eq.) previously dissolved in $1 \mathrm{~mL}$ DMSO was added to the flask followed by a catalytic amount of DMAP (previously dissolved in $200 \mu \mathrm{L}$ DMSO). pH was adjusted to 8 with DIEA and reaction was left under magnetic stirring for $72 \mathrm{~h}$. The solvent was removed under reduced pressure, and the product was re-suspended in $300 \mu \mathrm{L}$ of Milli-Q water and purified by size exclusion chromatography (G25, PD-10 column).

This journal is (C) The Royal Society of Chemistry 20xx
Fractions were lyophilized and the obtained solids analyzed by $1 \mathrm{H} N M R$ and DOSY $\left(\mathrm{D}_{2} \mathrm{O}\right)$.

1H NMR $\delta \mathrm{H}\left(300 \mathrm{MHz}, \mathrm{D}_{2} \mathrm{O}\right): 4.41(1 \mathrm{H}, \mathrm{m}), 3.74(68 \times \mathrm{H}+4 \mathrm{H} \mathrm{m})$, $3.07(2 \mathrm{H}, \mathrm{m}), 1.82(4 \mathrm{H}, \mathrm{m})$. x: percentage of modification.

PLO-PEG2000 (P4). All reagents were weighed in separate recipients and purged under N2 flow before and during their solution. P4 was synthesized using DMTMM with a modification of a previously published method [37]. In a two-necked round bottom flask fitted with a stir bar and two septae, MPEG(2000)$\mathrm{COOH}(0.01 \mathrm{eq}, 0.0021 \mathrm{mmol})$ dissolved in $1 \mathrm{~mL}$ anhydrous DMSO. To the resulting suspension, DMTMM·BF4 (0.02 eq., $0.004 \mathrm{mmol}$ ) dissolved in $0.3 \mathrm{~mL}$ of anhydrous DMSO was added dropwise and stirred at RT for $15 \mathrm{~min}$. Subsequently, PLO50 (MW 195 per unit, $0.2 \mathrm{mmol}, 1$ eq.) dissolved in $1 \mathrm{~mL}$ anhydrous DMSO was added, and the reaction mixture was stirred for 72 h. The solvent was removed under reduced pressure, and the product re-suspended in $300 \mu \mathrm{L}$ of Milli-Q water and purified by size exclusion chromatography (G25, PD-10 column). Fractions were lyophilized and the obtained solids analyzed by $1 \mathrm{H}$ NMR and DOSY $\left(\mathrm{D}_{2} \mathrm{O}\right)$

1H NMR $\delta \mathrm{H}\left(300 \mathrm{MHz}, \mathrm{D}_{2} \mathrm{O}\right): 4.41(1 \mathrm{H}, \mathrm{m}), 3.74(44 \times \mathrm{H}+4 \mathrm{H} \mathrm{m})$, $3.07(2 \mathrm{H}, \mathrm{m}), 1.82(4 \mathrm{H}, \mathrm{m})$. x: percentage of modification.

\subsection{NMR}

\section{H-NMR Experiments}

NMR spectra were recorded at $27^{\circ} \mathrm{C}(300 \mathrm{~K})$ on an Avance III $500 \mathrm{MHz}$ Bruker spectrometer equipped with a $5 \mathrm{~mm}$ TBI broadband probe or a 300 Ultrashield from Bruker (Billerica, MA, USA). Data were processed with the software Mestrenova (Bruker $\mathrm{GmbH}$, Karlsruhe, Germany). Samples were prepared at the desired concentration in $\mathrm{D}_{2} \mathrm{O}$.

\section{Diffusion Experiments}

Pulsed-field gradient NMR spectroscopy was employed to measure translational diffusion by fitting the integrals or intensities of the NMR signals to the Stejskal-Tanner equation $[38,39]: I=10 \exp [-\operatorname{D} \gamma 2 g 2 \delta 2(\Delta-\delta / 3)]$ where I is the observed intensity, 10 the reference intensity (unattenuated signal intensity), D the diffusion coefficient, $v$ the gyromagnetic ratio 
of the observed nucleus, $g$ the gradient strength, $\delta$ the length of the gradient, and $\Delta$ the diffusion time. Two-dimensional diffusion-ordered NMR spectroscopy (DOSY) was performed with a stimulated echo sequence using bipolar gradient pulses. The lengths of delay were held constant at $\Delta=100 \mathrm{~ms}$, and 32 spectra of 64 scans, 10 each were acquired with the strength of the diffusion gradient varying between $5 \%$ and $95 \%$. The lengths of the diffusion gradient and the stimulated echo were optimized for each sample.

\subsection{Gel Permeation Chromatography}

Gel Permeation Chromatography (GPC) was performed in an AF2000 system from Postnova Analytics (Landsberg, Germany) using aqueous media containing $0.1 \mathrm{M}$ of $\mathrm{NaNO}_{3}$ and $0.005 \%$ $(w / w)$ sodium azide as an additive. The system was configured to work on GPC mode with an isocratic pump (PN1130) an autosampler (PN5300), a 6 refractive index (RI, PN3150), 21 angle-multi angle light scattering (MALS, PN3621) and an ultraviolet-visible (UV-VIS) (PN3211) detectors. A working flow rate of $0.7 \mathrm{~mL} / \mathrm{min}$ for $40 \mathrm{~min}$ at $30^{\circ} \mathrm{C}$ was employed with one TSKgel G50000PWxI-CP column. $40 \mu \mathrm{L}$ of a polymer solution of $5 \mathrm{mg} / \mathrm{mL}$ was injected each time.

\subsection{PLO Degradation Studies}

A cocktail of bacterial proteases from Streptomyces griseus was used as a degradation matrix. A compound analogous to P2, but synthesized with PLO150 instead PLO50, was used to explore the stability of the PLO polymer. This derivative was spiked into the protease cocktail matrix at a final polymer concentration of $10 \mathrm{mg} / \mathrm{mL}$, with the matrix diluted to a protein concentration of $10 \mathrm{mg} / \mathrm{mL}$ and buffered to $\mathrm{pH} 6.0$ with $20 \mathrm{mM}$ Tris. The mixture was incubated at $37^{\circ} \mathrm{C}$ under agitation (300 rpm), and $120 \mu \mathrm{L}$ aliquots were removed at each desired time point and analyzed by GPC under the same conditions detailed in section 1.3.

\section{Preparation and Characterization of siRNA polyplexes}

\subsection{Polyplex formation - N/P ratio Optimization}

$500 \mathrm{ng}$ of dsDNA/siRNA and the calculated amount of polymer at indicated charge-ratio (+/-) or amine to phosphate ratio (N/P) were diluted in separate tubes in 20 mM HEPES buffer at pH 7.4 each. Only protonable nitrogens, not amide nitrogens, were considered in the +/- ratio and N/P ratio calculations. The nucleic acid and the polymer solution were mixed by rapidly pipetting up and down (at least five times) and incubating for $20 \mathrm{~min}$ at RT before next usage.

Electrophoresis assays were carried out to ensure polyplex formation. A 2.5 wt\% agarose gel was prepared by dissolving agarose in TAE buffer (Tris base, acetic acid, and EDTA) and boiling at $100{ }^{\circ} \mathrm{C}$. After cooling to $50^{\circ} \mathrm{C}$ and GelRed addition, the agarose gel was set in an electrophoresis unit. Polyplexes containing $500 \mathrm{ng}$ of siRNA/dsDNA in $20 \mu \mathrm{L}$ HEPES $20 \mathrm{mM}$ and loading buffer were placed into the sample lanes. Electrophoresis was performed at $80 \mathrm{~V}$ for $80 \mathrm{~min}$.

\subsection{Size and Zeta-potential Determination}

DLS measurements were performed using a Malvern ZetaSizer NanoZS instrument, equipped with a $532 \mathrm{~nm}$ laser at a fixed scattering angle of $173^{\circ}$ (Malvern Instruments, Worcestershire, UK). Polyplex solutions were filtered through a $0.45 \mu \mathrm{m}$ cellulose membrane filter and measured in a DTS 1070 cell. Size distribution was measured (diameter, $\mathrm{nm}$ ) for each compound in triplicate preparations, each with $n>3$ measurements. For size measurements, polyplex solutions were prepared in HEPES $20 \mathrm{mM} \mathrm{pH}=7.4$ at $0.012-0.014 \mathrm{mg} / \mathrm{mL}$ and measured at $25^{\circ} \mathrm{C}$. Automatic optimization of beam focusing and attenuation was applied for each sample. Zeta-potential measurements were performed using disposable folded capillary cells, provided by Malvern Instruments Ltd. Polymer solutions were prepared under the same conditions as for size measurements. The zeta (द)-potential was calculated using the Smoluchowski model. Accordingly, $10-30$ sub-runs of $10 \mathrm{~s}$ at $25^{\circ} \mathrm{C}(\mathrm{n}=3)$ were measured.

TEM images were recorded using a JEOL 2100 transmission electron microscope. Samples of polyplexes were applied directly onto carbon film on 200 mesh copper grids. Excess of the sample was carefully removed by capillarity, and the grids were immediately stained with one drop of $2 \%$ uranyl acetate for $30 \mathrm{~s}$. Excess of staining was likewise removed by capillarity.

\subsection{Gel Electrophoresis Studies of Polymer Stability}




\section{Heparin Displacement Assay}

The strength of the dsDNA/siRNA-polymer interaction was examined by heparin competitive displacement assay [40]. Polyplexes were incubated with heparin $(0.75 \mathrm{IU} / \mathrm{mL} ; 50 \mathrm{IU} / \mathrm{mL}$ and $250 \mathrm{IU} / \mathrm{mL}$ ) and evaluated by gel electrophoresis/UV illumination as described in Section 2.1 to observe dsDNA/siRNA release.

\section{Plasma Stability by Gel Shift Assay}

Polyplexes prepared as in section 2.1 were incubated in a solution containing $20 \%$ mouse serum at $37{ }^{\circ} \mathrm{C}$ and different incubation times ( $0 \mathrm{~h}, 2 \mathrm{~h}, 3 \mathrm{~h}$, and $5 \mathrm{~h}$ ) to determine plasma stability. Subsequently, an agarose gel electrophoresis assay was performed using the same protocol described above.

\section{Cell Culture Media Stability by Gel Shift Assay}

Polyplexes were incubated in a solution containing $80 \%$ cell culture media (B16-F10 or OPC media) at $37{ }^{\circ} \mathrm{C}$ and different incubation times $(0,1,5$, and $24 \mathrm{~h})$ to ensure cell culture media stability. Subsequently, an agarose gel electrophoresis assay was performed using the same protocol described above.

\section{Storage Stability by Gel Shift Assay}

Polyplexes prepared as in section 2.1 were stored at $4^{\circ} \mathrm{C}$ for 15 days to study polyplex stability during storage. Subsequently, an agarose gel electrophoresis assay was performed using the same protocol described above.

\subsection{Circular Dichroism}

Circular dichroism (CD) spectroscopy was performed with a J815 CD Spectrometer (JASCO Corporation) using a Peltier thermostated cell holder (PTC-423, JASCO 15 Corporation) with a recirculating cooler (JULABO F250, JASCO Corporation). A nitrogen flow $(\sim 2.7 \mathrm{~L} / \mathrm{min})$ was filtered through the spectrometer and controlled with a nitrogen flow monitor (Afriso Euro-Index). The samples (polymer, polyplex, and dsDNA) were dissolved in phosphate buffer (PB) pH 7.4, at 0.15 $\mathrm{mg} / \mathrm{mL}$. Samples were measured repeatedly $(n=3)$ in a quartz cuvette with $\mathrm{d}=0.1 \mathrm{~cm}$ at $20^{\circ} \mathrm{C}$. Obtained molar ellipticities were plotted as mean residue ellipticity.

\subsection{Polyplex Haemocompatibility Evaluation}

Red blood cells (RBC) were isolated from fresh mouse blood obtained by cardiac puncture after death and placed in a tube with an anticoagulant compound (0.5M EDTA, 1/10 volume) on ice. Blood was diluted with PBS pH 7.4 up to $10 \mathrm{~mL}$ and then centrifuged $\left(3000 \mathrm{rpm}, 10 \mathrm{~min}, 4^{\circ} \mathrm{C}, \times 3\right)$, removing the supernatant after each centrifugation and re-suspending the cells in sterile PBS. The final RBC pellet was weighed and resuspended at $2 \%(\mathrm{v} / \mathrm{v})$ in sterile PBS. Stock solutions were dissolved in PBS adjusted to $\mathrm{pH} 6.5$ or 7.4 and citrate solution adjusted to $\mathrm{pH} 5.5$ to mimic different stages in the endolysosomal pathway to study the hemolytic activity of the polymers and the polyplexes. Samples were added to wells $(n=3,100 \mu L)$ covering the concentration range 0.1-0.005 $\mathrm{mg} / \mathrm{mL}$ of systems $(0.1,0.05,0.01$, and $0.005 \mathrm{mg} / \mathrm{mL})$. Buffer at the corresponding $\mathrm{pH}$ was used as a control. Triton X-100 1\% $(\mathrm{w} / \mathrm{v})$ was used as a positive control to determine a $100 \% \mathrm{RBC}$ lysis and dextran $(2 \mathrm{mg} / \mathrm{mL})$ was used as a negative control. The plates were then incubated at $37{ }^{\circ} \mathrm{C}$ for $1 \mathrm{~h}$. Plates were centrifuged $\left(3000 \mathrm{rpm}, 10 \mathrm{~min}, 20^{\circ} \mathrm{C}\right.$ ) and the supernatant of each well was transferred into a new plate to assess hemoglobin $\mathrm{Hb}$ ) release. The hemoglobin released was assessed by measuring the absorbance at $570 \mathrm{~nm}$ using a Wallac Victor2 plate reader. The percentage of hemolysis of each sample was calculated relative to $100 \%$ hemolysis obtained from incubation with Triton-X 100.

\section{Cell Culture Studies}

\subsection{Cell-Culture}

Murine melanoma cells B16-F10-luc-G5 (B16-F10) cells which stably express firefly luciferase were cultured at $37^{\circ} \mathrm{C}$ in a $5 \%$ $\mathrm{CO}_{2}$ atmosphere using DMEM medium supplemented with $10 \%$ FBS, $2 \mathrm{mM}$ L-glutamine, $100 \mathrm{IU} / \mathrm{mL}$ penicillin, $100 \mathrm{\mu g} / \mathrm{mL}$ streptomycin. Cells were maintained at $37^{\circ} \mathrm{C}$ in an atmosphere of $5 \% \mathrm{CO}_{2}$ and $95 \%$ air, and they underwent passage twice weekly when $80 \%$ cell confluence was reached.

Primary OPCs were isolated using A2B5-primary antibody (Millipore) and anti-IgM Microbeads for positive magnetic cell sorting following Miltenyi Biotech indications with some modifications, as previously described [41] (Supporting 
Information). Briefly, P4-P7 rats were euthanized via an intraperitoneal injection of Pentoject and then decapitated following schedule 1 procedures (Animal Scientific Procedure Act 1986). The brains were cut into small pieces and digested with a papain solution containing $1: 25$ papain and $1: 100$ DNase in HALF ("Hibernate A low fluorescence" made in-house) for 30 $\min$ at $35{ }^{\circ} \mathrm{C}$. Following tissue digestion, papain was removed with HBSS (-/-) (without $\mathrm{Ca} 2+$ and $\mathrm{Mg} 2+$ ) washes and via centrifugation. The tissue was then triturated with HALF with $1 \mathrm{X}$ B27 and $2 \mathrm{mM}$ sodium pyruvate first, and the single-cell suspension was passed through a $70 \mu \mathrm{m}$ strainer. The remaining tissue bits were triturated a second and third time with HALF with $0.1 \%$ pluronic acid and $2 \mathrm{mM}$ sodium pyruvate and the single-cell suspension transferred through a $70 \mu \mathrm{m}$ strainer. The single-cell suspension was centrifuged for $20 \mathrm{~min}$ at $800 \mathrm{xg}$ in a 22.5\% Percoll (GE Healthcare) solution with DMEM F12. Following centrifugation, Percoll was removed by aspiration, and the cells were washed with HBSS (-/-). Cells were incubated with A2B5 antibody (MAB312) for $25 \mathrm{~min}$ at $4{ }^{\circ} \mathrm{C}$ in wash buffer (0.5\% BSA, $2 \mathrm{mM}$ sodium pyruvate, $2 \mathrm{mM}$ EDTA and $10 \mathrm{ug} / \mathrm{ml}$ insulin in $1 \mathrm{X}$ PBS). Excess of antibody was washed away with HBSS (-/-), and cells were incubated with secondary IgMmicrobeads for $15 \mathrm{~min}$ at $4{ }^{\circ} \mathrm{C}$ in wash buffer. Excess of antibody was again removed by washing with HBSS (-/-), and the cells were magnetically sorted following the manufacturer's instructions (Miltenyi Biotech). Cells were eluted in OPC media with $20 \mathrm{ng} / \mathrm{mL}$ of bFGF and $20 \mathrm{ng} / \mathrm{mL}$ PDGF-AA and plated in poly-D-lysine coated coverslips. The OPCs cells were kept under in culture and media with growth factors $(20 \mathrm{ng} / \mathrm{mL}$ bFGF and $20 \mathrm{ng} / \mathrm{mL}$ PDGF-AA) was added every other day.

\subsection{Cell cytotoxicity Studies}

\section{MTS Assay for Cell Viability Evaluation}

B16-F10 cells were seeded into sterile $96-$ well plates at a density of 10,000 cells per well. After $24 \mathrm{~h}$, the culture medium was replaced with $80 \mu \mathrm{L}$ of fresh growth medium containing $10 \%$ FBS. Then, $20 \mu \mathrm{L}$ of parent polymers or polyplexes solution $(0.2$ $\mu \mathrm{m}$ filter sterilized) at different + /- or N/P ratios were added. Studies were performed in triplicate ( $n=8$ samples). $48 \mathrm{~h}$ posttransfection, $10 \mu \mathrm{L}$ of a solution containing MTS/phenazine methosulfate (PMS) (20:1) were added to each well, and the cells were incubated for a further $2 \mathrm{~h}$. The optical density of each well was measured spectrophotometrically at $490 \mathrm{~nm}$ using a Wallac Victor2 plate reader. The absorbance values were represented as the percentage of cell viability relative to the viability of untreated control cells $(100 \%)$.

\section{LDH assay for cell viability}

The toxicity of polyplexes in primary OPCs was ascertained using an LDH-Cytotoxicity II kit following the instructions provided by the supplier. Toxicity/viability was normalized to non-treated cells ( $100 \%$ viability) and samples lysed with a $10 \%$ solution of Triton $\mathrm{X}-100$ ( $0 \%$ viability). Assays were performed on the supernatant of treated/non-treated OPCs at $48 \mathrm{~h}$ posttransfection. This time point included a medium change at $6 \mathrm{~h}$ post-transfection.

\section{In vitro transfection}

\subsection{Luciferase Silencing}

B16-F10 cells were seeded in sterile 96-well plates in $100 \mu \mathrm{L}$ medium $(10,000$ cells per well). After $24 \mathrm{~h}$, the medium was exchanged for $80 \mu \mathrm{L}$ fresh medium. The formed polyplexes containing 500 ng of siRNA (scrambled siRNA or luciferase silencing siRNA) per well were added in a volume of $20 \mu \mathrm{L}$ to each well and incubated at $37^{\circ} \mathrm{C}$. Lipofectamine RNAiMAX at non-toxic optimum N/P ratio with scrambled siRNA or luciferase silencing siRNA were used as positive controls for transfection efficiency, according to manufacturer instructions. All experiments were performed in triplicate. $48 \mathrm{~h}$ after transfection, cells were treated with $20 \mu \mathrm{L}$ of Bright-Glo reagent (luciferin $(150 \mu \mathrm{g} / \mathrm{mL})$ in PBS). Luciferase activity was spectrophotometrically quantified using a Wallac Victor2 plate reader ( $\lambda$ em $535 \mathrm{~nm}$ ).

\subsection{DR6 silencing in OPCs}

$24 \mathrm{~h}$ prior to transfection, penicillin, and streptomycin were removed from the cell media to avoid interference with the Lipofectamine transfection. Polyplexes, parent polymers or Lipofectamine RNAiMAX complexes were incubated for $6 \mathrm{~h}$ at cell culture conditions. Then, the medium was removed, and new cell media with growth factors (bFGF and PDGF-AA) was 
added. RNA was collected $48 \mathrm{~h}$ after transfection, and protein collection was performed 4 days after transfection.

\subsubsection{Gene expression Through Real-Time qPCR}

Primary OPCs were seeded in sterile 12-well plates (previously coated with PDL $5 \mu \mathrm{g} / \mathrm{mL}$ ) at 80,000 cell/well. Every other day the medium was exchanged for fresh medium. Compounds (polyplexes with scrambled siRNA or DR6-silencing siRNA, parent polymers, and Lipofectamine RNAiMAX with scramble siRNA or DR6-silencing siRNA) were incubated for $6 \mathrm{~h}$ at $37^{\circ} \mathrm{C}$ and then replaced by fresh media. $48 \mathrm{~h}$ post-transfection, total RNA was extracted using QIAzol Lysis reagent and the protocol provided by the supplier. RNA was quantified using a NanoDrop 2000 spectrophotometer with purity assessed by means of A260/A280 and A260/A230 ratios. From 500 ng of total RNA, cDNA was generated using a High-Capacity cDNA Reverse Transcription kit using random hexamer primers. qRT-PCR was subsequently performed using TaqMan reagents (TaqMan Fast Universal PCR Master Mix [2x] and FAM-labeled TaqMan Gene Expression Assays) and an Applied Biosystems 7500 Fast realtime PCR system. Mouse Gapdh (VIC labeled) was used as a reference gene for determining relative Tnfrsf21 gene expression using the $2^{-\Delta \Delta C t}$ method [42]. Each biological sample was measured in triplicate, and the experiment was performed with three independent biological replicates.

\subsubsection{Protein Expression Analysis}

Primary OPCs were seeded in sterile 6-well plates (previously coated with PDL as previously indicated) at 200,000 cells/well. Every other day, fresh medium was added to the cells. Compounds (polyplexes with scramble siRNA or DR6-silencing siRNA, parent polymers, and Lipofectamine with scramble siRNA or DR6-silencing siRNA) were incubated for $6 \mathrm{~h}$ at $37^{\circ} \mathrm{C}$ and then replaced with fresh media. Cells were collected 4 days post-transfection. Proteins were extracted by solubilization in RIPA buffer with the addition of Complete Protease Inhibitor Cocktail and Halt Phosphatase Inhibitor Cocktail, and $1 \mathrm{mM}$ PMSF to inhibit serine proteases. Cell lysates were centrifuged at $10,000 \mathrm{rpm}$ for $10 \mathrm{~min}$ at $4^{\circ} \mathrm{C}$. Supernatants were collected, and protein concentration was determined using Bio-Rad Protein Assay. Sample volumes equivalent to $15 \mu \mathrm{g}$ of total protein were mixed with $5 \times$ SDS sample buffer, boiled for $5 \mathrm{~min}$ and separated through $12.5 \%$ SDS-PAGE gels. After electrophoresis, the proteins were transferred to nitrocellulose membranes by electrophoretic transfer. The transfer was confirmed by Ponceau S staining. The membranes were blocked in $5 \%$ skimmed milk for $1 \mathrm{~h}$, rinsed, and incubated overnight at $4^{\circ} \mathrm{C}$ with the primary antibodies: DR6/TNFRSF21 (1:500 dilution), cleaved Caspase-3 (1:5000 dilution), PARP (1:500) and $\beta$-actin (1:1000). Excess antibody was then removed by washing the membrane in PBS/0.1\% Tween 20, and the membranes were incubated for $1 \mathrm{~h}$ with horseradish peroxidase-conjugated secondary antibodies: mouse anti-rabbit IgG (1:5000), goat antirabbit IgG (1:4000), mouse anti-rabbit IgG (1:5000) and antimouse IgG (1:10000) (respectively). After washing with PBS/0.1\% Tween 20, immuno-detection was performed using the ECL Prime Western Blotting Detection system, according to the manufacturer's instructions. Densitometry measurements were performed using Fiji, with each protein band being normalized to the $\beta$-actin loading controls.

\subsubsection{Immunofluorescent Studies}

OPCs were seeded on a $9 \mathrm{~mm}$ glass coverslip (VWR) at a density of 2000 cells/coverslip with daily supplementation $10 \mathrm{ng} / \mathrm{mL}$ of PDGF-AA and $10 \mathrm{ng} / \mathrm{mL}$ of bFGF. After three days, the coverslips were transferred to 48 well-plates and siRNA experiments performed as described above. Cells were fixed after $48 \mathrm{~h}$ of incubation with 4\% PFA for $15 \mathrm{~min}$ and then washed twice with PBS prior to proceeding to immunocytochemistry.

Cells were blocked with 5\% normal donkey serum (NDS) with $0.01 \%$ triton for $1 \mathrm{~h}$ at RT. Cells were then incubated with primary antibodies diluted in blocking solution for $1 \mathrm{~h}$ at RT: rabbit Olig2 (1:500), mouse CNP (1:500). Excess primary antibody was washed away with PBS, and cells were incubated with secondary antibodies in blocking solution for $1 \mathrm{~h}$ at RT. Upon secondary antibody incubation, the excess of antibody was washed out, and cells were incubated again with primary antibody against $\mathrm{O} 4$ (1:500) for $1 \mathrm{~h}$ at RT in blocking solutions. Again, the excess of antibody was washed out with PBS, and the cells were incubated with the corresponding secondary for $1 \mathrm{~h}$ at RT. After washing away the excess of the secondary antibody, the cells were stained with Hoechst (1:5000) and coverslips 
were mounted with Fluoromount G. Images were taken using a

Leica SP5 confocal.

\section{Statistical Analyses}

Data from the experiments were analyzed using one-way ANOVA and Bonferroni posthoc for pairwise comparison. In all cases, differences were considered to be significant when ${ }^{* * *}$ p $<0.001 ;{ }^{* *} p<0.01 ; *<0.05 ;$ ns: nonsignificant.

\section{Conflicts of interest}

There are no conflicts to declare.

\section{Acknowledgments}

The authors would like to thank Dr. Stuart P. Atkinson for English revision. This work has been supported by the Spanish Ministry of Science and Innovation (SAF2016-80427-R) Generalitat Valenciana and Val I+D Postdoc fellowship (ICS, ref APOSTD/2015/024). Part of the equipment used in this work has been funded by Generalitat Valenciana and cofinanced with European Regional Development Fund (FEDER) funds (PO FEDER of Comunitat Valenciana 2014-2020).

\section{References}

1. S. H. Lee, Y. Y. Kang, H. E. Jang, H. Mok, Adv Drug Deliv Rev 104, 78-92 (2016).

2. D. Adams et al., N Engl J Med 379, 11-21 (2018).

3. Y. Huang. Mol Ther Nucleic Acids 6, 116-132 (2017).

4. https://www.alnylam.com/alnylam-rnai-pipeline/clinicaltrials/

5. http://investors.alnylam.com/news-releases/news-releasedetails/alnylam-submits-marketing-authorization-applicationeuropean

6. R. Kanasty, J. R. Dorkin, A. Vegas, D. Anderson, Nat Mater 12 967-977 (2013).

7. R. R. Nikam, K. R. Gore, Nucleic Acid Ther 28, 209-224 (2018).

8. C. Chakraborty, A. R. Sharma, G. Sharma, C. G. P. Doss, S. S Lee, Mol Ther Nucleic Acids 8, 132-143 (2017).

9. M. Foldvari et al., J Control Release 240, 165-190 (2016).

10. M. Zheng, W. Tao, Y. Zou, O. C. Farokhzad, B. Shi, Trends Biotechnol 36, 562-575 (2018).

11. H. Yin et al., Non-viral vectors for gene-based therapy. Nat Rev Genet 15, 541-555 (2014).

12. S. Gao et al., J Control Release 243, 357-369 (2016).

13. F. Zahir-Jouzdani , F. Mottaghitalab, M. Dinarvand, F. Atyabi, Journal of Drug Delivery Science and Technology 45, 428-441 (2018).

14. Y. Xiang, N. N. L. Oo, J. P. Lee, Z. Li, X. J. Loh, Drug Discov Today 22, 1318-1335 (2017)

15. D. Oupick, Biology and Medicine 12, 449 (2016).

16. R. Duncan, Nat Rev Drug Discov 2, 347-360 (2003).

17. F. Rodriguez-Otormin, A. Duro-Castano, I. Conejos-Sanchez, M. J. Vicent, Wiley Interdiscip Rev Nanomed Nanobiotechnol 11 e1532 (2019).

18. S. Jeyapalan et al., Am J Clin Oncol 37, 444-449 (2014).
19. C. J. Langer et al., J Thorac Oncol 3, 623-630 (2008).

20. M. Nishikawa et al., Gene Ther 7, 548-555 (2000).

21. C. W. Pouton et al., J Control Release 53, 289-299 (1998).

22. Q. L. Lu, G. Bou-Gharios, T. A. Partridge, Gene Ther 10, 131 142 (2003).

23. E. Ramsay, J. Hadgraft, J. Birchall, M. Gumbleton, Int J Pharm 210, 97-107 (2000).

24. S. P. Chamarthy, J. R. Kovacs, E. McClelland, D. Gattens, W. S. Meng, Mol Immunol 40, 483-490 (2003).

25. D. A. Christian et al., Eur J Pharm Biopharm 71, 463-474 (2009).

26. M. Sung, G. M. Poon, J. Gariépy, Biochim Biophys Acta 1758 355-363 (2006).

27. V. Mahairaki et al., Tissue Eng Part A 17, 855-863 (2011).

28. H. Ge et al., Sci Rep 5, 15535 (2015)

29. E. G. Z. Centeno, H. Cimarosti, A. Bithell, Molecular neurodegeneration 13, 27-27 (2018).

30. M. D. Darrabie, W. F. Kendall, E. C. Opara, Biomaterials 26 6846-6852 (2005).

31. H. Margus, K. Padari, M. Pooga, Mol Ther 20, 525-533 (2012). 32. D. M. Wingerchuk, J. L. Carter, Mayo Clin Proc 89, 225-240 (2014).

33. S. Mi et al., Nat Med 17, 816-821 (2011).

34. M. Kunishima et al., Tetrahedron 55, 13159-13170 (1999).

35. Z. J. Kaminski et al., J Am Chem Soc 127, 16912-16920 (2005). 36. A. J. van der Vlies, C. P. O'Neil, U. Hasegawa, N. Hammond, J. A. Hubbell, Bioconjug Chem 21, 653-662 (2010).

37. M. Barz, A. Duro-Castano, M. J. Vicent, Polymer Chemistry 4, 2989-2994 (2013).

38. T. Tu, W. Fang, X. Bao, X. Li, K. H. Dötz, Angew Chem Int Ed Engl 50, 6601-6605 (2011).

39. C. C. Tsou, S. S. Sun, Org Lett 8, 387-390 (2006).

40. T. Merdan et al., Bioconjug Chem 14, 989-996 (2003).

41. B. Neumann, I. Kazanis, Front Biosci (Schol Ed) 8, 29-43 (2016).

42. K. J. Livak, T. D. Schmittgen, Methods 25, 402-408 (2001).

43. O. Zagorodko, J. J. Arroyo-Crespo, V. J. Nebot, M. J. Vicent, Macromol Biosci 17, (2017).

44. A. Niño-Pariente et al., Macromol Biosci, (2017).

45. A. Duro-Castano, I. Conejos-Sánchez, M. Vicent, Polymers 6, 515 (2014).

46. M. J. Vicent, M. Barz, F. Canal, I. Conejos-Sánchez, D.-C. Castaño, A. (2012).

47. M. Durand, J. C. Maurizot, H. N. Borazan, C. Helene, Biochemistry 14, 563-570 (1975).

48. C. Helene, J. L. Dimicoli, FEBS Lett 26, 6-10 (1972).

49. V. V. Kostjukov, N. M. Khomytova, M. P. Evstigneev, Biopolymers 91, 773-790 (2009).

50. R. Gambari, C. Nastruzzi, Biochem Pharmacol 47, 599-610 (1994).

51. Q.-Y. Yu et al., Polymers 9, 362 (2017).

52. O. Schäfer, M. Barz, Chem. Eur. J., 24, 12131 (2018).

53. S. Uchida et al., Molecular Therapy 20, 1196-1203 (2012).

54. C. Curtis, M. Zhang, R. Liao, T. Wood, E. Nance, Wiley Interdiscip Rev Nanomed Nanobiotechnol 9 (2017).

55. M. J. Joralemon, S. McRae, T. Emrick, Chem Commun (Camb) 46, 1377-1393 (2010)

56. E. A. Nance et al., Sci Transl Med 4, 149ra119 (2012).

57. D. Li, G. Kagan, R. Hopson, P. G. Williard, Journal of the American Chemical Society 131, 5627-5634 (2009).

58. Y. J. Wang, H. Therien-Aubin, W. E. Baille, J. T. Luo, X. X. Zhu, Polymer 51, 2345-2350 (2010).

59. R. Duncan, H. R. Gilbert, R. J. Carbajo, M. J. Vicent, Biomacromolecules 9, 1146-1154 (2008).

60. D. Huesmann et al., Macromolecules 47, 928-936 (2014).

61. A. Duro-Castano et al., Advanced Materials 29, 1702888 (2017).

62. S. E. Barrett et al., Int J Pharm 466, 58-67 (2014).

63. S. E. Barrett et al., J Control Release 183, 124-137 (2014). 
64. M. Trop, Y. Birk, The Biochemical journal 116, 19-25 (1970). 65. K. Ohkawa, T. Kitsuki, M. Amaike, H. Saitoh, H. Yamamoto, Biomaterials 19, 1855-1860 (1998).

66. H. Yamamoto, Y. Hirata,. Macromolecules 28, 6701-6704 (1995).

67. G. Lundblad, M. Elander, L. Manhem, Acta Chemica Scandinavica B 29, 937-947 (1975).

68. M. Bier, Electrophoresis: Theory, Methods, and Applications. (Elsevier Science, 2013).

69. J.-K. Y. Tan, D. L. Sellers, B. Pham, S. H. Pun, P. J. Horner, Frontiers in Molecular Neuroscience 9, (2016).

70. C. Hörz et al., Macromolecules, 48,7, 2074-2086 (2015).

71. N. C. Garbett, P. A. Ragazzon, J. B. Chaires, Nature protocols 2, 3166-3172 (2007).

72. J. Kypr, I. Kejnovska, D. Renciuk, M. Vorlickova, Nucleic acids research 37, 1713-1725 (2009).

73. C. A. Sprecher, W. A. Baase, W. C. Johnson, Jr., Biopolymers 18, 1009-1019 (1979).

74. M. F. Maestre, J. C. Wang, Biopolymers 10, 1021-1030 (1971) 75. S. F. Ausar, S. B. Joshi, C. R. Middaugh, Methods in molecular biology 434, 55-80 (2008).

76. A. Krivitsky et al., Nanomedicine: nanotechnology, biology, and medicine 14, 303-315 (2018).

77. L. Han, C. Tang, C. Yin, Biomaterials 34, 5317-5327 (2013).

78. H. Engelberg, Circulation 23, 573-577 (1961).

79. P. Ferruti et al., Macromolecules 33, 7793-7800 (2000).

80. A. Nikolaev, T. McLaughlin, D. D. M. O'Leary, M. TessierLavigne, Nature 457, 981-989 (2009).

81. G. Pan et al., I FEBS Lett 431, 351-356 (1998).

82. G. Huang et al., Cell death \& disease 4, e841-e841 (2013).

83. Y. Wang et al., Journal of molecular neuroscience, 56, 966-976 (2015).

84. H. Zhao et al., The Journal of experimental medicine 194, 1441-1448 (2001).

85. D. Fujikura et al., Death receptor 6 contributes to autoimmunity in lupus-prone mice. Nature communications 8 , 13957 (2017).

86. R. Baror, B. Neumann, M. Segel, KJ Chalut, SPJ Fancy, DP Schafer, RJM Franklin. Glia. Jul;67(7):1374-1384 (2019)

87. M. Tewari et al., Cell 81, 801-809 (1995).

88. F. J. Oliver et al., J Biol Chem 273, 33533-33539 (1998).

89. AG De La Fuente, S Lange, ME Silva, GA Gonzalez, H Tempfer, $P$ van Wijngaarden, $C$ Zhao, $L$ Di Canio, A Trost, L Bieler, $P$ Zaunmair, P Rotheneichner, A O'Sullivan, S Couillard-Despres, O Errea, MA Mäe, J Andrae, L He, A Keller, LF Bátiz, C Betsholtz, L Aigner, RJM Franklin, FJ Rivera. Cell Rep. 22;20(8):1755-1764 (2017).

90. T. Lourenço et al., Sci Rep 6, 21563 (2016)

91. J. C. Louis, E. Magal, D. Muir, M. Manthorpe, S. VaronJ Neurosci Res 31, 193-204 (1992).

92. K. Pringproa, J. Kumnok, R. Ulrich, W. Baumgärtner, K. Wewetzer, International Journal of Developmental Neuroscience 26, 283-291 (2008).

93. S. Pluchino et al., Nature 436, 266-271 (2005). 